\title{
As relações dos sistemas de saneamento e a saúde da população: um estudo em um distrito de um município no Rio Grande do Norte
}

\author{
The relationships of sanitation systems and population's health: a study in a district of a \\ city in Rio Grande do Norte
}

Las relaciones de los sistemas de saneamiento y la salud de la población: un estudio en un distrito de una ciudad en Rio Grande do Norte

Mariana Torres Correia de Mello ${ }^{1 *}$, Luciana Torres Correia de Mello².

\begin{abstract}
RESUMO
Objetivo: Analisar os aspectos relacionados ao saneamento básico e sua relação com a saúde da população de um distrito de um município do Rio Grande do Norte (RN). Métodos: Trata-se de um estudo do saneamento básico local considerando a caracterização dos aspectos abastecimento de água, esgotamento sanitário, limpeza urbana e drenagem, com diagnóstico realizado por meio de questionário e observações. Resultados: O abastecimento de água do referido distrito é executado pela Companhia de Águas e Esgotos do Rio Grande do Norte (CAERN). Em relação a qualidade da água, há conformidade com o estabelecido na norma do Ministério da Saúde. O sistema de esgotamento sanitário representa, atualmente, cerca de $30 \%$ das residências locais, denotando que a maioria adota soluções individuais para o destino dos efluentes sanitários, como fossa séptica. O destino final dos resíduos apresenta característica de aterro controlado em mal funcionamento. Não há sistema de drenagem, acarretando um grave problema no saneamento básico, devido as águas da chuva escoarem em direção ao maior declive, podendo causar erosão do solo urbano. Conclusão: Conclui-se que o ambiente e a população são negligenciados pelas gestões públicas, podendo ocasionar significativos problemas futuros para a saúde da população e seu bem-estar social.
\end{abstract}

Palavras-chave: Saneamento básico, Qualidade de vida, Saúde da População.

\begin{abstract}
Objective: To analyze the aspects related to basic sanitation and its relationship with the health of the population of a district, of a city in Rio Grande do Norte (RN). Methods: This is a study of local basic sanitation considering the aspect characterization of water supply, sanitary sewage, urban cleaning and drainage, diagnosed through a questionnaire and observations. Results: The district water supply is performed by the Rio Grande do Norte Water and Sewage Company (CAERN). Regarding water quality, it complies with the established in the Ministry of Health standard. The sewage system currently represents around $30 \%$ of local residences, denotating that most adopt individual solutions for the destination of sanitary effluents, as a septic tank. The final destination of the waste present a malfunctioning controlled landfill feature. There is no drainage system, causing a serious problem in basic sanitation, due to rainwater run off towards the steepest slope, may cause erosion of urban soil. Conclusion: It is concluded that the environment and the population are neglected by public management, which may cause significant future problems for the population's health and social welfare.
\end{abstract}

Key words: Basic Sanitation, Life's Quality, Population's Health.

1Universidade Federal do Rio Grande do Norte (UFRN), Natal-RN. *E-mail: marianatcm@yahoo.com.br 2Universidade Federal Rural do Semiárido (UFERSA), Angicos-RN.

SUBMETIDO EM: $8 / 2019$

ACEITO EM: 9/2019

PUBLICADO EM: 10/2019

REAS/EJCH | Vol.11(15) | e1492 | DOI: https://doi.org/10.25248/reas.e1492.2019 Página 1 de 9 


\section{RESUMEN}

Objetivo:analizarlos aspectos relacionados conelsaneamiento básico y surelaciónconlasalud de lapoblación de un distrito de unmunicipio de Rio Grande do Norte (RN). Métodos: Este es unestudio de saneamiento local que considera lacaracterización de los aspectos de suministro de agua, alcantarillado, limpieza urbana y drenaje, diagnosticados mediante uncuestionario y observaciones. Resultados: El suministro de agua de este distrito es realizado por la Compañía de Agua y Alcantarillado de Río Grande do Norte (CAERN). Encuanto a lacalidaddelagua, cumpleconelestándardelMinisterio de Salud. El sistema de alcantarillado representa actualmentealrededordel $30 \%$ de loshogareslocales, lo que indica que lamayoría adopta soluciones individuales para el destino delalcantarillado, como una fosa séptica El destino final de losresiduostiene una función de rellenosanitario controlado que no funciona correctamente. No hayun sistema de drenaje, lo que causa un grave problema enelsaneamiento básico, ya que elagua de lluvia se filtra hacialapendiente más alta, lo que puede causar laerosióndelsuelo urbano. Conclusión: se concluye que lagestión pública descuida elmedio ambiente y lapoblación, lo que puede causar problemas futuros significativos para lasalud y elbienestar social de lapoblación.

Palabras clave: saneamiento básico, calidad de vida, salud de lapoblación.

\section{INTRODUÇÃO}

O saneamento básico é a composição das questões relacionadas a água, efluentes, resíduos, sendo efluentes e resíduos o que o homem descarta e que comumente não é aproveitado, incluindo os efluentes pluviais. Contudo, o significado de saneamento básico é bem mais abrangente, não podendo ser diferenciado de questões sociais relacionadas ao meio ambiente e, principalmente, da saúde da população. Conforme aponta a Organização Mundial de Saúde (WHO, 1993), a qualidade de vida da população relaciona-se a fatores físicos, químicos, biológicos, sociais e psicológicos inseridos no meio ambiente e denominados saúde ambiental, no qual se inclui o conceito de saneamento básico, por isso a importância de se estudar o saneamento com um viés ambiental e social.

O saneamento básico abrange ações sociais, ambientais e econômicas que visam alcançar a salubridade ambiental. Segundo o Guia para a Elaboração de Planos Municipais de Saneamento (BRASIL, 2006), Saneamento Ambiental foi historicamente desenvolvido para alcançar níveis crescentes de salubridade ambiental, no qual compreendem o abastecimento de água, o esgotamento sanitário, o manejo de resíduos sólidos urbanos, o manejo de águas pluviais urbanas, juntamente com o controle de vetores de doenças, promovendo a melhoria das condições de vida urbana e rural.

Vale salientar ainda que, no desenvolvimento da cidade, a procura pelo local saudável é o início de um processo. Assim, em termos de planejamento, faz-se necessário identificar e compreender as relações entre os sistemas de saneamento e a cidade, tanto em seus aspectos físicos, ambientais e de ocupação do solo quanto em seus aspectos técnicos. É evidente que fatores mais complexos têm papel preponderante na criação das cidades e na sua localização, como, por exemplo, aqueles de caráter econômico. Entretanto, para o seu desenvolvimento, o lado prático do saneamento entra em cena (BRASIL, 2006), fazendo deste não só um fator preponderante, como também essencial para o planejamento urbano de qualquer cidade (MANÇANO MR, 2010).

Com relação ao abastecimento de água potável, segundo o Ministério das Cidades (BRASIL, 2010), as cidades só existem se houver disponibilidade hídrica regular, importante para o abastecimento da população e suas necessidades gerais, no qual são responsáveis pra o conforto da população, qualidade de vida e desenvolvimento socioeconômico. Hoje as cidades não conseguem se desligar dessas questões, por isso devem ser inseridas previamente no planejamento urbano (MANÇANO MR, 2010) e das necessidades de consumo específicas. Porém, a água consumida para vários fins é transformada em efluentes e, este gerado necessita de coleta, transporte, tratamento e disposição final das águas residuárias, adequadamente, conforme normas sanitárias e ambientais, pois apresenta em sua composição elementos poluentes para o meio ambiente, podendo comprometer a qualidade de vida da população (RIBEIRO JW e ROOKE MS, 2010). 
Outra questão componente do saneamento básico, são os resíduos sólidos produzidos pelo homem do qual devem receber o devido tratamento e destinação final adequado. Como resíduos, cita-se os alimentos não utilizados, a matéria prima proveniente dos processos produtivos já utilizados e processados e que não serão utilizados, dentre outros. Tais resíduos se degradam em processo lento, tornando-se fontes de poluição e contaminação, além de fontes geradoras de doenças (MINISTÉRIOS DAS CIDADES, 2006).

Follador KP (2015) coloca que a precariedade do saneamento básico adotado nos vários municípios, se não adequado, desencadeia diversas conseqüências das quais, os veiculadores de doenças humanas das quais poderiam ser evitadas por meio de uma instalação dos aspectos de saneamento básico adequado, como um tratamento de esgoto adequado e eficiente, bem como os efluentes pluviais e uma destinação final correta dos resíduos sólidos, todos previsto em lei.

Sendo assim, este artigo tem como objetivo analisar os aspectos relacionados ao saneamento básico e sua interligação com a saúde da população, como fator determinante na qualidade de vida da sociedade, com ênfase em um distrito de um município no Rio Grande do Norte (RN).

\section{MÉTODOS}

Esta pesquisa trata-se de um estudo envolvendo a caracterização dos aspectos quantitativos e qualitativos, primários e secundários acerca do saneamento básico em um município no RN, com ênfase em um distrito específico. O diagnóstico do saneamento básico (água, esgoto, resíduos sólidos e drenagem) da área de estudo foi realizado com base no levantamento de dados primários e secundários. Os dados secundários foram levantados a partir de pesquisa bibliográfica a órgãos oficiais em busca de documentos que dispunham de dados sobre o abastecimento de água, o tratamento e destinação do esgoto, a destinação final dos resíduos sólidos e a drenagem local.

O diagnóstico a partir de dados primários foi elaborado por meio de três etapas de atividades executadas no período aproximado de abril a outubro de 2011:

i) coleta de informações com os profissionais envolvidos no setor de saneamento referente aos aspectos analisados (abastecimento de água, esgotamento sanitário, destinação dos resíduos sólidos e sistema de drenagem);

ii) observações empíricas na localidade (ruas, local de despejo final de resíduos e efluentes) com visitas in loco;

iii) coleta de informações do mapeamento da rede de esgoto, água - no Setor de Projetos da Companhia de Águas e Esgotos do Rio Grande do Norte (CAERN) - e resíduos sólidos.

\section{RESULTADOS E DISCUSSÕES}

O município específico estudado neste artigo apresenta 11.385 habitantes, segundo o Instituto Brasileiro de Geografia e Estatística (IBGE) (2010) e ocupa o 65 lugar entre os municípios indutores do turismo no Brasil (MINISTÉRIO DO TURISMO, 2010), sendo o segundo destino mais visitado do RN (GOVERNO DE $\operatorname{ESTADO}(\mathrm{RN})$, [s.d.]). A maior parcela da população encontra-se na zona urbana (6.861 habitantes). Para a densidade demográfica do último Censo Demográfico de 2010, o município destacado na pesquisa apresentou o maior valor com 111,81 hab/km² (IBGE, 2010).

Segundo o IBGE, o município dispõe de 19,8\% de domicílios com esgotamento sanitário adequado, sendo $75 \%$ desses domicílios com saneamento considerado semi-adequado, 23\% considerado adequado e 2,1\% considerado inadequado. Em relação ao abastecimento de água, segundo a Pesquisa Nacional de Saneamento Básico (2008), existem 2.582 economias abastecidas, sendo 1.757 ativas. O volume de água tratada distribuída por dia é de $1.152 \mathrm{~m}^{3}$. Em relação ao tipo de abastecimento de água, em 2000, 91,2\% das residências é abastecida por rede geral, $5,7 \%$ por poço ou nascente na propriedade e 3,1\% por outra forma não identificada. 


\section{Sistema de Abastecimento de Água}

O sistema de abastecimento de água da zona urbana do distrito é executado pela CAERN. O serviço de Água apresenta 1.728 ligações totais cadastradas, das quais 1.331 são ligações ativas, ou seja, pagam a conta mensalmente; 14 são as ligações suprimidas que a CAERN cancela por não pagarem a conta, porém o usuário acaba religando por conta própria e recebe multa. Há ainda informações das ligações novas que, por exemplo, em um mês foram feitas seis ligações.

A CAERN, para abastecer o local, utiliza atualmente quatro poços tubulares públicos que se encontram ativos e localizados dentro da zona urbana em área cercada e com proibição de despejos. Sua alimentação é o manancial subterrâneo. Existem outros poços particulares localizados em pontos específicos como pousadas, hotéis e condomínios, onde não se encontram ligados a rede geral de água. Quanto a esses poços, a CAERN monitora alguns. Mensalmente, é realizada a leitura dos volumes produzidos em cada poço.

O tratamento da água captada de cada poço é realizado mediante "cloração" executado de 3 em 3 dias e são feitas análises de água mensalmente, medindo o nível de cloro residual livre; nitrato, pH, turbidez, coliformes totais e fecais, conforme a Tabela1, e a cada semestre é realizada a análise na água bruta do poço.

Tabela 1 - Análise de água dos poços durante um mês.

\begin{tabular}{ccccccc}
\hline POço & $\begin{array}{c}\text { Cloro } \\
\text { residual } \\
\text { livre } \\
\text { (Miligrama } \\
\text { por Litro } \\
\text { mg/L) }\end{array}$ & $\begin{array}{c}\text { Nitrato } \\
\text { (Miligrama } \\
\text { por Litro } \\
\text { mg/L) }\end{array}$ & $\begin{array}{c}\text { Potencial } \\
\text { Hidrogeniônico }(\mathbf{p H})\end{array}$ & $\begin{array}{c}\text { Turbidez (em } \\
\text { Unidades } \\
\text { Nefelométricas } \\
- \text { UNT) }\end{array}$ & $\begin{array}{c}\text { Coliformes } \\
\text { Total }\end{array}$ & $\begin{array}{c}\text { Coliformes } \\
\text { fecais }\end{array}$ \\
\hline VMP* $^{*}$ & 0,2 a 2,0 & 10,0 & 6,0 a 9,5 & 5,0 & AUSÊNCIA & AUSÊNCIA \\
$\begin{array}{c}\text { Poço } \\
1\end{array}$ & 1,12 & 2,6 & 5,27 & 0,73 & Ausência & Ausência \\
$\begin{array}{c}\text { Poço } \\
2\end{array}$ & 0,43 & 0,0 & 5,72 & 1,02 & Ausência & Ausência \\
$\begin{array}{c}\text { Poço } \\
3\end{array}$ & 0,74 & 0,0 & 4,99 & 0,48 & Ausência & Ausência \\
$\begin{array}{c}\text { Poço } \\
4\end{array}$ & 0,0 & 0,0 & 6,44 & Ausência & Ausência \\
\hline
\end{tabular}

* Valores máximos permitidos pela Portaria 518/2004 do Ministério da Saúde.

Fonte: Mello MTC, Mello LTC, 2019, baseado nos dados do CAERN de 2011.

No que concerne a qualidade da água dos poços, de acordo com as amostras coletadas pela CAERN, os valores se encontram em conformidade com o que estabelece a Portaria 518/2004 do Ministério da Saúde, excetuando-se o pH que apresenta valores fora do padrão estabelecido ou recomendado por esta portaria. Tais valores informam que a qualidade da água distribuída ainda não está comprometida. Porém, ressalta-se que o pH é o único parâmetro disforme com o exigido. As águas servidas recebem o mesmo destino final que os efluentes sanitários. E não houve relatos de falta de água, apenas por pouco tempo quando se precisa executar alguma manutenção.

\section{Sistema de Esgotamento Sanitário}

O sistema de esgotamento sanitário do distrito apresenta atualmente511ligações cadastradas, representando em torno de $30 \%$ das residências beneficiadas com esse serviço, o que implica dizer que a grande maioria das residências ainda não está ligada à rede coletora de esgoto, adotando soluções individuais para o destino dos efluentes sanitários como fossa séptica. Dessas 511 ligações cadastradas são coletados um volume de $7.070 \mathrm{~m}^{3}$ de esgoto por mês, onde $4.770 \mathrm{~m}^{3}(67,50 \%)$ residenciais, $1.985 \mathrm{~m}^{3}(28,05 \%)$ comerciais, $105 \mathrm{~m}^{3}(1,48 \%)$ industriais e $210 \mathrm{~m}^{3}$ (2,97\%) público. O destino final desse esgoto são as lagoas de ETE. 
A Estação de Tratamento de Esgoto (ETE) funciona da seguinte forma: todo o esgoto que chega passa por uma "caixa de areia", na qual passa por um gradeamento e são separados materiais sólidos e grandes através de uma triagem manual. Em seguida, o esgoto passa para um tanque, onde é posto cal para diminuir o mal cheiro e acelerar a decantação do material sólido, a partir de então o esgoto é bombeado, passando por uma tubulação até uma área cercada com três lagoas, uma facultativa e duas de maturação.

O tratamento desses tipos de lagoas acontece por meio de um processo natural, e podem compreender três zonas: anaeróbia, aeróbia e facultativa. O esgoto líquido entra por uma extremidade da lagoa e percorre vários caminhos durantes dias, até sair pela outra extremidade. O primeiro processo é a sedimentação da matéria orgânica no fundo da lagoa. Essa matéria orgânica sedimentada passa por um tratamento anaeróbio. A parte da matéria não sedimentada, que fica dissipada, passa por um tratamento aeróbio. No processo aeróbio se faz necessária a presença de oxigênio que é introduzido naturalmente pelas algas da lagoa por meio da fotossíntese (Disponível em http://www.fec.unicamp.br/ bdta/esgoto/lagoas.html).

Quando bem dimensionada, raramente uma lagoa facultativa produz maus odores, porém recomenda-se que não sejam construídas junto às áreas residenciais. Deve se levar em consideração o sentido predominante dos ventos e localizá-las a pelo menos 500 metros de residências (Disponível em www.ceset.unicamp.br).

As Lagoas de Maturação não constituem, por si só, um sistema de tratamento, e sim, são utilizadas como tratamento complementar de efluentes secundários. Elas devem ser dimensionadas com taxas de carregamento orgânicos muito inferiores do que aquelas empregadas para dimensionamento de lagoas facultativas. Comumente se empregam duas lagoas em série, com profundidade entre 1,0 e1,5 m (ou menor), com função de melhorar a qualidade do efluente tratado e de possibilitar maior eficiência na remoção de organismos patogênicos (Disponível: www.ceset.unicamp.br ).

A CAERN executa as análises do esgoto bruto; do efluente facultativo; do efluente da maturação 01 e do efluente da maturação 2 (Tabela 2).

Tabela 2 - Análise do esgoto coletado ao longo das lagoas facultativa e maturação.

\begin{tabular}{|c|c|c|c|c|c|c|c|c|c|c|}
\hline $\begin{array}{l}\text { PONTO DE } \\
\text { COLETA }\end{array}$ & $\begin{array}{c}\mathrm{DBO}^{\mathrm{a}} \\
5 \\
\left(\mathrm{O}_{2} \mathrm{~m}\right. \\
\mathrm{g} / \mathrm{L})\end{array}$ & $\begin{array}{c}D Q O^{b} \\
\left(\mathrm{O}_{2} \mathrm{~m}\right. \\
\mathrm{g} / \mathrm{L})\end{array}$ & $\begin{array}{l}\text { Fósfo } \\
\text { ro } \\
\text { Total } \\
\text { (Pmg/ } \\
\text { L) }\end{array}$ & $\begin{array}{c}\text { Nitrogê } \\
\text { nio } \\
\text { Amonia } \\
\text { cal } \\
\mathrm{NH}_{3}\end{array}$ & $\begin{array}{c}\text { Oxigênio } \\
\text { Dissolvido } \\
\left(\mathrm{O}_{2}^{-} \text {em }\right. \\
\text { Miligrama } \\
\text { por Litro - } \\
\text { mg/L) }\end{array}$ & $\begin{array}{l}\text { Poten } \\
\text { cial } \\
\text { Hidro } \\
\text { geniô } \\
\text { nico } \\
\text { (pH) }\end{array}$ & $\begin{array}{l}\text { Sólidos } \\
\text { Sedimen- } \\
\text { táveis } \\
\text { (ml/L) }\end{array}$ & $\begin{array}{c}\text { Sólidos } \\
\text { Suspen } \\
\text { sos } \\
\text { (em } \\
\text { Miligra } \\
\text { ma por } \\
\text { Litro - } \\
\text { mg/L) } \\
\end{array}$ & $\begin{array}{l}\text { Sulfato } \\
\left(\mathrm{SO}_{4}{ }^{2--}\right. \\
\text { em } \\
\text { Miligra } \\
\text { ma por } \\
\text { Litro - } \\
\text { mg/L) }\end{array}$ & $\begin{array}{c}\text { Sulfeto } \\
\text { (S'-em } \\
\text { Miligram } \\
\text { a por } \\
\text { Litro - } \\
\text { mg/L) }\end{array}$ \\
\hline VMP $^{*}$ & $\begin{array}{c}120^{* *} \\
60^{*} \\
\end{array}$ & $s / d$ & $1,27^{\star}$ & $\begin{array}{c}20,0 \\
(1,5)^{\star \star \star}\end{array}$ & $>6,0$ & $\begin{array}{c}6,0 \mathrm{a} \\
9,0\end{array}$ & 1,0 & 500 & 250 & $\begin{array}{c}1,0 \\
(0,05)^{\star * *}\end{array}$ \\
\hline $\begin{array}{c}\text { Esgoto } \\
\text { Bruto } \\
\end{array}$ & $\begin{array}{c}2304 \\
0\end{array}$ & $\begin{array}{c}1.891 \\
0\end{array}$ & 8,80 & 25,98 & - & 8,8 & 0,3 & 147,0 & 13,1 & 2,10 \\
\hline $\begin{array}{c}\text { Efluente } \\
\text { Facultativo I }\end{array}$ & $\begin{array}{c}1224 \\
4\end{array}$ & 815,0 & 5,65 & 14,89 & 2,4 & 7,0 & 0,4 & 380,0 & 12,9 & 1,85 \\
\hline $\begin{array}{c}\text { Efluente } \\
\text { Maturação I }\end{array}$ & 116,1 & 640,0 & 4,91 & 9,96 & 4,5 & 7,3 & 0,4 & 241,0 & 18,8 & 1,81 \\
\hline $\begin{array}{l}\text { Efluente } \\
\text { Maturação } \\
\text { II }\end{array}$ & 88,4 & 582,0 & 1,00 & 8,84 & 6,5 & 7,4 & 0,6 & 263,0 & 14,3 & 1,65 \\
\hline
\end{tabular}

* Valores máximos permitidos pela Resolução CONAMA 357

** Valores máximos permitidos pela Resolução CONAMA 430.

*** Valores máximos permitidos pela Portaria do Ministério da Saúde 518/2004 para água destinada ao consumo humano. aDemanda Bioquímica de Oxigênio bemanda Química de Oxigênio

Fonte: Mello MTC, Mello LTC, 2019, baseado nos dados do CAERN de 2011.

Considerando as Resoluções CONAMA 357/2005 e 430/2011, observa-se que os seguintes valores se encontram acima dos Valores Máximos Permitidos (VMP), quais sejam: 
- DBO que apresenta valores extremamente altos em seu estado de esgoto bruto e seu tratamento até sua última etapa do processo o efluente de maturação II apresenta diminuição considerável, e a amostra no momento do lançamento encontra-se com valor de $88,4 \mathrm{O} 2 \mathrm{mg} / \mathrm{L}$ ainda com nível acima do permitido (< 60 O2mg/L). Porém, segundo a Resolução CONAMA 430/2011 este valor, em sua última etapa da ETE, apresenta-se dentro do valor máximo permitido.

-Sulfeto: o efluente tratado na lagoa de maturação II apresenta valor de saída de 1,65 S2-mg/L, acimado valor máximo permitido pela resolução 430/2011 que é de 1,0 S2-mg/L. O enxofre é um dos elementos presentes nos esgotos e ocorrem na forma de sulfeto e sulfatos. Os esgotos municipais com presença de valores de enxofre elevados, principalmente sulfetos na forma de Sulfeto de Hidrogênio (H2S), e em condições anaeróbicas podem causar sérios problemas de odor e que podem entrar no fluxo da atmosfera, em superfície, atingir áreas ocupadas e causar importantes problemas de saúde pública e ambiental, relacionados a exposições contínuas de seres humanos a estas substâncias odorantes, como os trabalhadores de ETEs, além de moradores, transeuntes e trabalhadores em áreas próximas à estação de tratamento. Medidas corretivas e preventivas deveriam e devem ser priorizados à luz da saúde pública e ambiental (LILIAMTIS TB e MANCUSO PCS, 2004).

Levando-se em consideração que: 1) o maior percentual de contribuição do volume de esgoto coletado no município vem das residências, aproximadamente $67 \%$; 2) que o processo de tratamento de esgoto atualmente instalado no referido distrito é insuficiente e não apresenta o processo de tratamento completo; 3 ) que existe uma demanda de turistas na cidade que aumenta sazonalmente; 4) que o esgoto parcialmente tratado é infiltrado diretamente no solo arenoso, poroso e de alta permeabilidade. Observa-se que não há um planejamento municipal que pense os problemas advindos da geração desses esgotos com o aumento populacional sujeito a esses períodos sazonais. Ressalta-se também que a injeção no solo de esgoto parcialmente tratado pode, dependendo da carga, contaminar o lençol freático e, por fim, contaminar a água para abastecimento à população, uma vez que ambos se encontram no mesmo lençol d'água subterrâneo.

Deve-se levar em consideração que esta sobrecarga no sistema somente não ocorreu ainda devido ao município está somente $30 \%$ ligado à rede, o que é muito pouco para um município que tem uma injeção grande de recursos oriundos da atividade turística.

\section{Sistema de Limpeza Urbana}

Os serviços de coleta e destino final dos resíduos sólidos no distrito são gerenciados pela Secretaria de Meio Ambiente e Serviços Urbanos do município no qual se encontra, e realizam a limpeza urbana, coleta de lixo, remoção de entulhos, disposição final dos resíduos, coleta de resíduos de saúde (terceirizado), varrição, capinação, podação e, administração e manutenção de praças e cemitérios.

A coleta de resíduos sólidos abrange toda a área urbana e conta com uma frota de dois caminhões caçambas e um caminhão compactador. A coleta ocorre todos os dias no período da madrugada até o início da manhã, devido o maior acesso nas vias nesse horário. O local de destino final dos resíduos locais apresenta característica de aterro controlado (Figura 1).

Segundo o Instituto de Pesquisas Tecnológicas (IPT) (2000), o aterro controlado é uma técnica de disposição de resíduos sólidos municipais no solo, sem causar danos ou riscos à saúde pública e à sua segurança, minimizando os impactos ambientais.

Esse método, apesar de confinar os resíduos sólidos, cobrindo-os com material inerte, produz poluição, porém localizada. Geralmente, não dispõe de impermeabilização de base (comprometendo a qualidade das águas subterrâneas), nem de sistemas de tratamento do percolado (termo empregado para caracterizar a mistura entre o chorume, produzido pela decomposição do lixo, e a água de chuva que percola o aterro) ou o biogás gerado.

Esse método é preferível ao lixão, mas devido aos problemas ambientais que causa, principalmente em um solo altamente permeável como o do referido município, e aos seus custos de operação, é de qualidade bastante inferior ao aterro sanitário. 
Figura 1 - Visão mais aproximada do aterro controlado

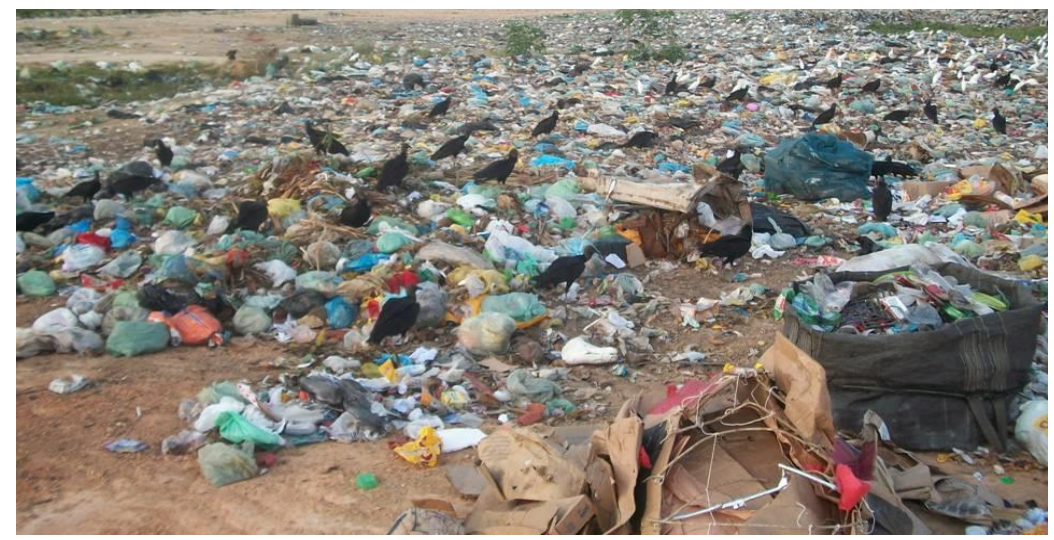

Fonte: Mello MTC, Mello LTC, 2019, baseado nos dados do CAERN de 2011.

No aterro controlado do município há a presença de 16 catadores de lixo que vendem os resíduos catados para duas empresas, uma de Natal e outra do Espírito Santo (ES). No momento da visita ao aterro, encontraram-se catadores coletando o lixo sem nenhum equipamento de proteção individual e não há nenhum trabalho social sendo realizado com esses catadores.

Observa-se mais uma vez a situação precária do saneamento municipal, no que diz respeito à gestão dos resíduos sólidos. Em síntese, a situação do aterro controlado (ou insuficientemente controlado) do município apresenta os seguintes impactos ambientais: i) Contaminação das áreas do entorno por resíduos dispersos pela ação dos ventos devido à falta de cobertura de areia em certas áreas da cava; ii) Contaminação do aquífero subterrâneo por meio do percolante (chorume+águas pluviais) contaminador do aterro devido a não impermeabilização do fundo das cavas, cujo solo arenoso é hidrologicamente de alta permeabilidade; iii) Dispersão de agentes patogênicos pelo vento em direção às áreas de entorno; iv) Proliferação de insetos e roedores disseminadores de doenças; v) Degradação da paisagem natural.

O ritmo do crescimento do turismo, de construção de condomínios de segunda residência, de hotéis e pousadas, de restaurantes aumentou a produção de resíduos sólidos, porém, não se seguiu o mesmo ritmo de investimento em saneamento pelos gestores públicos do município.

Um fator que se apresenta problemático a esse recolhimento é a estrutura das ruas do distrito que são estreitas e sem calçamento adequado, impedindo a passagem do caminhão compactador. Apesar disso, os donos de hotéis, pousadas, condomínios, comércios e residências levam o seu lixo a locais próximo onde o caminhão possa passar.

\section{Sistema de Drenagem de Águas Pluviais}

Não há sistema de drenagem no distrito, acarretando um dos mais graves problemas do saneamento básico, pois as águas da chuva escoam conforme a topografia, ou seja, em direção as áreas mais baixas e onde há maior declive adquirindo maior velocidade e podendo causar erosão do solo urbano.

O desenvolvimento acelerado e desorganizado de pequenos distritos e municípios propicia a impermeabilização da superfície por meio da construção de prédios, ruas pavimentadas, calçadas, entre outros. A impermeabilização do solo reduz ou impede a infiltração das águas das chuvas, e gera um escoamento volumoso superficial (NAIME R, 2010).

Segundo Naime R (2010), a incorporação de superfícies semipermeáveis e impermeáveis torna a superfície do terreno mais lisa, o que aumenta a velocidade do escoamento. $O$ armazenamento em depressões da superfície também é reduzido, aumentando ainda mais o excedente da precipitação escoado superficialmente. Portanto, após o processo de ocupação do solo, a respostado solo aos diferentes tipos de chuva muda radicalmente. 
O Plano Diretor do referido município do RN, mesmo sem apresentar sistema de drenagem, apontou na Subseção II - Da drenagem pluvial, as seguintes diretrizes no Artigo 71: "Os serviços urbanos de drenagem de águas pluviais deverão ser garantidos, preferencialmente, através de medidas não estruturais, e em seguida de medidas estruturais, que compreendem o sistema físico construído, de modo a propiciar segurança e conforto aos ocupantes de edificações existentes".

Institui ainda no Artigo 72 para os empreendimentos que para facilitar a drenagem natural das águas pluviais, cada terreno ao ser utilizado deverá deixar uma área permeável do mesmo, na equivalência de no mínimo 40\%, na zona urbana e de expansão urbana, conforme o caso, e 50\% na zona rural, salvo exceções contidas nos quadros de prescrições para cada área, de modo a impedir que a água drenada em cada terreno seja carreada para outro local.

E o poder público municipal no Plano Diretor ainda se apresenta, em seu Artigo 73 como o gestor do sistema local de manejo de águas pluviais e drenagem urbana, cabendo a ele coordenar e executar, diretamente ou através de consórcio público ou concessão, todos os serviços relativos ao manejo de águas pluviais. Porém, segundo a Secretaria responsável pelos serviços urbanos e meio ambiente, não há nenhum projeto de drenagem em vista ou em planejamento para ser executado, há apenas discussões, contudo, nada concreto.

\section{CONCLUSÃO}

Os resultados da pesquisa apresentam que o ambiente e a população do distrito estudado são negligenciados pelas gestões públicas, separando os interesses dos empresários dos interesses socioambientais. Veem-se descaso e condições problemáticas relacionadas ao saneamento básico do município, podendo ocasionar problemas futuros significativos e ameaçadores para o bem-estar da população e do ambiente. Neste sentido, ressalta-se a importância do saneamento básico como uma atividade estratégica alinhada a melhoria das condições da saúde pública e o desenvolvimento do município como um todo no qual colabora para a diminuição da incidência de doenças e consequente redução com as despesas de assistência médica hospitalar.

\section{REFERÊNCIAS}

1. BRASIL. Guia para a elaboração de planos municipais de saneamento. Ministério da Cidades. - Brasília: Ministério das Cidades, 2006.

2. BRASIL. O Estatuto da Cidade: comentado = The City Statute of Brazil: a commentary/organizadores Celso Santos Carvalho, Ana Claudia Rossbach. - São Paulo: Ministério das Cidades: Aliança das Cidades, 2010.

3. BRASIL. IBGE - Censo 2010.

4. BRASIL. Índice de Competitividade do Turismo Nacional - 65 Destinos Indutores do Desenvolvimento Turístico Regional - Relatório Brasil 2010 / Luiz Gustavo Medeiros Barbosa (Organizador) - Brasília: Ministério do Turismo, 2010

5. RN. Site do Governo do Estado: Disponível em http://www.rn.gov.br/conheca-orn/turismo/. Acesso em: 15 ago. 2011.

6. BRASIL. Ministério da Saúde. Secretaria de Vigilância em Saúde. Coordenação-Geral de Vigilância em Saúde Ambiental. Portaria MS n. 518/2004 / Ministério da Saúde, Secretaria de Vigilância em Saúde, Coordenação-Geral de Vigilância em Saúde Ambiental - Brasília: Editora do Ministério da Saúde, 2005.

7. BRASIL. Resolução CONAMA № 430, de 13 de maio de 2011, que dispõe sobre as condições e padrões de lançamento de efluentes, complementa e altera a Resolução no 357, de 17 de março de 2005, do Conselho Nacional do Meio Ambiente-CONAMA.

8. FOLLADOR K, PRADO GP, PASSOS MG, NOTHAFT SC. Saneamento básico: meio ambiente e saúde. Revista UNINGÁ Review, 2015; 23(1): 24-28.

9. IPT (Instituto de Pesquisas Tecnológicas) 2000. In: Resolução CONAMA № 357, de 17 de março de 2005, que dispõe sobre a classificação dos corpos de água e diretrizes ambientais para o seu enquadramento, bem como estabelece as condições e padrões de lançamento de efluentes, e da outras providencias.

10. LILIAMTIS TB, MANCUSO PCS. A aplicação de nitrato de amônio para o controle de odores em sistemas de coleta de esgotos sanitários. Revista Brasileira de Ciências Ambientais, 2004; 1(2): 37-45.

11. MANÇANO MR. Planejamento urbano e saneamento: contribuições para a elaboração de Planos Municipais. Rio de Janeiro, 2010. 
12. NAIME R. Metodologia Básica de Elaboração de Estudos de Saneamento Básico Municipal - Conceitos Básicos, Procedimentos Unitários e Processos de Gestão Integrada. São Leopoldo, 2010.

13. RIBEIRO JW, ROOKE MS. Saneamento básico e sua relação com o meio ambiente e a saúde pública. Trabalho de Conclusão de Curso (Especialização em Análise Ambiental) - Faculdade de Engenharia. Universidade Federal de Juiz de Fora, Juiz de Fora, 2010.

14. TIBAU DO SUL. Lei Complementar № 06 de 30 de dezembro de 2008 que dispõe sobre o Plano Diretor Participativo de Tibau Do Sul.

15. WORLD HEALTH ORGANIZATION - WHO. Environmental health services in Europe 1: an overview of practice in the 1990s. Bulgária, 1993. Disponível em: Acesso em 20 de agosto de 2019. 